\title{
Analysis of the Relationship between Wildfire Occurrences and Population Trend within the Shores of Lake Chad Basin Using Geoinformation
}

\author{
A. Dami \\ Department of Geography, University of Maiduguri, Borno State, Nigeria \\ Tel: 234-805-533-4965 E-mail: tonidamy@yahoo.com \\ H. K. Ayuba \\ Department of Geography, University of Maiduguri, Borno State, Nigeria \\ Tel: 234-802-452-3151Ｅ-mail: hk.ayuba@yahoo.com \\ M. Bila \\ Lake Chad Basin Commission, Tchad, Ndjamena, Chad \\ Tel: 235-252-6925Ｅ-mail: mbila@yahoo.com
}

Received: November 21, 2011 Accepted: December 19, $2011 \quad$ Published: March 1, 2012

doi:10.5539/jgg.v4n1p49 URL: http://dx.doi.org/10.5539/jgg.v4n1p49

\begin{abstract}
The study focuses and examines the relationship that exists between wildfire occurrence and the population trend within the shore of the Lake Chad. Geospatial analysis of fire pixel counts from MODIS images of the period 2001 -2009 was performed to determine the relationship between the wildfire occurrences and the population trend. The interpretation of SPOT panchromatic imagery in combination with field survey provided perimeters of settlements and estimated population in the area with the highest fire density in the north basin of Lake Chad. Major findings shows that the distribution of wildfires on the floor of Lake Chad for the period 2001-2009 reflected a spatial relationship with the distribution of vegetation and a temporal relationship with the seasonality of human-ecosystem interactions. The total number of fires recorded on the Lake floor is 25,690 leading to a burnt area of $19,274 \mathrm{~km}^{2}$. The population trend however, is increasing while that of wildfire occurrences is decreasing. The increasing trend in population against a decreasing trend in wildfire occurrences is an indication of the gradual conversion of the wild habitat between the old and the new shorelines of Lake Chad through human-ecosystem interactions from wild land to human occupation and exploitation.
\end{abstract}

Keywords: Wildfire, Population, Lake Chad, Trend, MODIS

\section{Introduction}

In the perspective of environmental science, fire effects is analysed in the context of major global environmental problems. Man has a history of altering natural ecosystem to suit his needs and fire is used as a tool in the exploitation of natural resources (land clearance for agriculture and settlement, bush burning for grazing etc). In our sub-region, the major environmental problem associated with fire use is indiscriminate bush burning. Fire use is considered a major factor in the alteration of our original pristine environment into the savannah ecosystem that dominates today in the arid and semi-arid biomes. Other effects of fire use recorded in our environment include loss of hydrogen, sulphur and carbon; elimination of seedlings of non fire-resistant species; destruction of humus and adverse soil physical and textual characteristics; adverse effects on soil macrofauna and destruction of soil microflora. Ehrlich et al. (1997) investigated whether areas of high density biomass burning is correlated with broad-scale land-cover changes in West Africa. The researchers could not conclusively find a correlation at the regional scale but were able to establish that fires mainly maintain land-cover in a state of equilibrium. However, this study therefore, intends to examine the relationship between the wildfire and the population trends in the area. 


\section{The Study Area}

The Lake Chad is located at the southern margins of the Sahara Desert lying between latitudes $12^{\circ} 30^{\prime}$ and $14^{\circ}$ $30^{\prime} \mathrm{N}$ and longitudes $13^{\circ}$ and $15^{\circ} 30^{\prime} \mathrm{E}$. Lake Chad is the second largest wetland in Africa. The lake lies within an endorheic basin of 2,434,000 $\mathrm{km}^{2}$ (UNEP, 2004). It has a mean depth of $4 \mathrm{~m}$ but a variable size depending on the volume of inflow into the Lake. The Lake Chad is replenished by flows from the Lake Chad drainage basin. The principal rivers of the Lake Chad drainage basin are the Chari Logone which rises in the Adamawa Plateau of the Cameroun and Mongos Hills in CAR, the Komadugu-Yobe which arose from the Jos Plateau and other smaller tributaries Yedseram and the El Beid (UNEP, 2004). Figure 2 is the location map of the Lake Chad hydrographic watershed with the LCBC Conventional basin while Figure 2 shows the study area of Lake Chad and its present shores in relation to the 1963 old shoreline.

The treaty signed by the Member States of the Lake Chad Basin Commission defined a geographical area of jurisdiction measuring $987,000 \mathrm{~km}^{2}$ called the "Conventional Basin". The current conventional basin was redefined in 1994 when the Republic of Central Africa became a member of the LCBC. The conventional basin is the active hydrological boundaries of the catchments of the principal tributaries to the Lake Chad.

The current population within the geographical basin is estimated to be approximately 37.2 million people with a population growth rate of between 2.5 and $3.0 \%$. Nigeria, Africa's most populous country hosts an estimated 22 million people (about 59\%) of the total population living in the basin. Whereas the northern and eastern peripheral countries, Algeria, Libya and Sudan, only have approximately 2.7 million inhabitants in the Basin (about 7\%), as it only represents just over $6 \%$ of the land area of the Basin (UNEP, 2004).

\subsection{Shrinking Lake Chad and People Adaptation}

Since 1984 when the United States Geological Survey (USGS) published Argon and LANDSAT satellites images of the shrinking Lake Chad, the attention of policy makers, scientists and the general public has been on the possibility that the Lake Chad might disappear. This state of thinking has been given added impetus in the sub-region by the resolution of the 10th Summit of Head of States and Governments of the Lake Chad Basin Commission Member States held in Ndjamena in 1998 that launched a campaign to save the Lake Chad from disappearing. The focus of the international community has been spurred by the dramatic satellite images showing how the surface area of Lake Chad has reduced from $24,000 \mathrm{~km}^{2}$ to less than $2,000 \mathrm{~km}^{2}$ in less than 40 years.

Climatic change has been identified as a contributor to the lost of surface area of the Lake Chad and constitute a primary threat to the Lake Chad Basin. In the recent past there is a long-term reduction in rainfall in the semi-arid regions of West Africa, on the order of 20 to $40 \%$ in parts of the Sahel (Nicholson, 2001). This reduction of rainfall has led to increased exploitation of the Lake Chad Basin water in irrigation by public irrigation agencies. Coe and Foley (2001), conducted a simulation study with the aim of discovering the contribution of climate variability and water management on the lost of water surface area in the Lake Chad. Their result demonstrated that human use of the water for irrigation accounted for the $50 \%$ of the observed change in lake area for the period 1960s and 1970s. We can therefore conclude that the increased exploitation of water to ensure food security is one of the adaptation mechanisms against climatic variability used by the governments of the Lake Chad Basin countries.

The poor riparian local actors are also adapting to the reality of climatic variability by migrating into the Lake bed for recessional agriculture. This migration is also leading to clearing wild habitat into new settlements and the new rural settlements are likely to lead to an increase in the demand for wood as a source of household energy and construction material.

Studies from other parts of the world have indicated that human activities leading to deforestation such as land clearing for agriculture and harvesting of wood products are associated with high incidence of wildfire occurrences detected by remote sensing (Dami, et al., 2011; Ayuba, et al., 2011; Eva, Brink and Simonetti, 2006; Eva and Lambin, 2000; Thenkabail, 1999).

\subsection{Degradation of Soil and Vegetation in the Lake Chad Basin}

The evidence of vegetation degradation in the Sahel as well as the Lake Chad Basin as a result of decadal climatic variability has been documented. Gonzalez (2001) reported that field data show that forest species richness in northwest Senegal fell 33\% from ca. 1945 to 1993. Densities of trees of $\mathrm{h} \geq 3 \mathrm{~m}$ declined 23\% from 1954 to 1989 . These changes shifted the Sahel, Sudan, and Guinean vegetation zones towards areas of higher rainfall at an average rate of 500 to $600 \mathrm{~m} \mathrm{yr}-1$. The changes also decreased human carrying capacity below actual population densities.

The diagnostic study of environmental degradation of the Lake Chad Basin (Dami, et al., 2011; Ayuba, et al., 2011; Kindler, et al., 1990) identified the major concerns on soil degradation to include sheet wash erosion, wind erosion 
of top soil(including deflation), abrasion of plant life by blown sand, fertility and tilth reduction, alkalinisation, salinisation, soil crust formation, sand barrier formation and compaction of top soil. The study noted that burning is one process that can contribute to these forms of soil degradation. In particular sheet erosion is initiated only when the plant canopy and grass cover becomes sparse that raindrop erosion, runoff and winds can move the top horizon of the soil.

Kindler et al (1990) reported that the degradation of the vegetation is attributed to drought and human influences. The human-related influences include:

overcutting of trees for fuelwood, construction wood and livestock browse;

over browsing by livestock;

trampling;

clearing for agriculture;

Clearing for human settlements (the number of villages in the Nigerian portion of Lake Chad rose from 40 to 100 between 1975 and 1988.

\section{Methodology}

The secondary dataset collected for this study involved the quantitative measurement of daily and weekly summary incidences of wildfire occurrences over the Lake Chad for the period 2000-2009. Each incidence consists of;

i) The location of the wildfire (Longitude and Latitude)

ii) The date of the wildfire occurrence

The first set of data was derived from satellite images acquired by the Moderate Resolution Imaging Spectrometer (MODIS) satellite sensor onboard Terra and Aqua Satellites. This dataset is also used in the derivation of the annual burnt area within the Lake Chad by using GIS analysis. The second set of data consists of population of villages located on the islands of the Lake Chad

The source of satellite-based fire information is from the MODIS fire products generated by the NASA Earth Observing System satellites Terra and Aqua. The combination of Terra and Aqua data provides four observations per day (Parkinson and Greenstone, 2000). MODIS data are distributed by the LP DAAC User Services, U.S. Geological Survey (USGS) Earth Resources Observation and Science (EROS) Center, USA.

The dataset is obtained from MODIS 8-day composited summary fire product (Terra MOD14A2 and Aqua MYD14A2). The product has 10 different pixel attributes with 7, 8 and 9 indicating low, nominal and high confidence fires respectively. The MODIS products are available for free or ordering from the Land Processes Distributed Active Archive Center (LP-DAAC) using the EOS Data Gateway web interface located at: http://wist.echo.nasa.gov.

The analysis of the data involved the following procedures;

Two SPOT panchromatic images of the areas showing the highest fire density in the north basin were purchased from SPOT Image Company of France.

Visual image interpretation of settlements is undertaken and perimeters of the settlements are digitized.

The area of four settlements whose population was obtained from the National Population Commission was used to calculate the average population per square kilometer for the lake.

The average population per square kilometer for the four settlements was use to arrived at the estimated population of the 387 villages identified in the SPOT imageries.

The annual population growth rates of 2.38 was applied to obtain the population from 2001-2009 to arrive at a projected population trend.

A map of population density per square kilometer was then created to arrive at the population distribution within the north basin.

\subsection{Statistical Techniques}

The study of fire occurrences in the Lake Chad is essentially a time series analysis of fire events which may carry trends that when discovered could form a basis for decision -making by resource managers. The aim of the statistical analysis is to discover the relationship between factors governing the trend in wildfire distribution in the Lake Chad shores. Accordingly, the following statistical techniques were applied. 


\subsection{Correlation Analysis}

Correlation analysis is used to determine if a relationship exists between two measured quantities. In this study correlation analysis is used to determine if there is a linear relationship between wildfire occurrences and population in the shores of Lake Chad.

\subsection{Linear Regression Analysis to Determine Trend}

Linear Regression analysis is use to model the relationship between independent and dependent variables. This statistical analysis aims to model the linear relationship that may exist between wildfire occurrences and population trend in the shores of Lake Chad.

\section{Result and Discussion}

\subsection{The Relationship between Wildfire Occurrences and Population on the Floor of Lake Chad}

A test for correlation between Year, Population and Fire count indicated a strong positive linear relation between year and projected population with an insignificant moderate negative relationship between projected population and Fire count (Table 2).

The table of probability of significant correlations at $95 \%$ confidence interval (Table 3 ) indicated that only the correlation between year and projected population could be model as a linear relationship. Based on the data collected during this study, the relationship between population and wildfire count shows a weak negative relationship. As the population increases, the wildfire count decreases. The weak negative relationship could be explained by the small number of years $(\mathrm{N}=9)$ of fire data used in the study.

However a link could exist between fire count and the population of 387 new villages with an estimated population of 56,421 that settled in the previously open water area between 1973 and 2009. Figure 3 is a map showing the location of settlements and the population density derived from SPOT panchromatic imagery of the area with the highest number of fires during the study period.

Despite the increased in population from probably zero in 1973 to 56,421 in 2010 , the number of fires shows a declining trend. The explanation for the declining trend in fire occurrences is the gradual conversion of the woodland on the shore of Lake Chad through human-ecosystem interactions into new settlements, cropland and cattle pastures (Dami, et al., 2011; Ayuba, et al., 2011)

The factors that could be responsible for this trend are

Decrease in Lake Chad water level

Population increase

\section{Establishment of new settlements}

Exploitation of the natural resources in the Lake floor through agriculture, animal husbandry and wood harvesting.

The implication of this trend in the Lake Chad is that there will be a gradual deforestation which could lead to an increase in wind speed subsequently increasing the rate of encroachment of the Sahara desert into particularly the north basin. Another implication of this is the modification and loss of habitat leading to the loss of biodiversity of both fauna and flora.

\section{Conclusion}

In conclusion, this study has shown that the distribution of wildfires in the shores of Lake Chad for the period 2001-2009 reflected a spatial relationship with the distribution of vegetation and a temporal relationship with the seasonality of human-ecosystem interactions.

The degradation of vegetation in the shores of Lake Chad for the period 2001-2009 occurs with a distinct spatial distribution and a predictable seasonal frequency resulting from human-ecosystem interactions such as farming, wood harvesting and transhumance.

This study therefore recommends that further studies needs to be undertaken to understand the contribution of other factors such as annual flood extent, winds and temperature in the relationship between vegetation distribution and distribution of wildfires.

\section{References}

Ayuba, H. K., Dami, A. \& Bila, M. D. (2011). Analysis of wildfire occurrences within the shores of Lake Chad using Geo-information technology. Journal of Remote Sensing \& GIS (JoRSG), 2(1), 1-7. 
Dami, A., Ayuba, H. K. \& Bila, M. (2011). spatio-temporal distribution of wildfire occurrences within the shores of Lake Chad based on remotely sensed data. Journal of Remote Sensing \& GIS (JoRSG), 2(2).

Ehrlich, D., Lambin, E. \& Malingreau, J. (1997). Biomass Burning and Broad-Scale Land-Cover Changes in West Africa. Remote Sensing of the Environment, 61(2), 201-209. http://dx.doi.org/10.1016/S0034-4257(97)00002-3

Eva, H., \& Lambin, E. F. (2000). Fires and land-cover change in the tropics: A remote sensing analysis at the landscape scale. Journal of Biogeography, 27, 765-776. http://dx.doi.org/10.1046/j.1365-2699.2000.00441.x

Eva, H., Brink, A. \& Simonetti, D. (2006). Monitoring Land Cover Dynamics in Sub-Saharan Africa : A pilot study using Earth observing satellite data from 1975 and 2000. Institute for Environment and Sustainability, Joint Research Centre of the European Commission. Luxembourg. pp. 12-16

Gonzalez, P. (2001). Desertification and a shift of forest species in the West African Sahel. Climate Research, 17, 217-228. http://dx.doi.org/10.3354/cr017217

Kindler, J., Warshall, P., Arnould, E. J., et al. (1990). The Lake Chad Conventional Basin - A Diagnostic Study of the Environmental Degradation. UNEP and UNSO. pp7-51

Nami, B. (2002). Environmental Degradation of the Lake Chad Basin: Implications for Food Security. In: UNEP, (2004). Fortnam, M. P. \& Oguntola, J. A. (eds), Lake Chad Basin, GIWA Regional assessment 43, University of Kalmar, Kalmar, Sweden. Pp30

Nicholson, S. E. (2001). Climatic and environmental change in Africa during the last two centuries. Climate Research, 17, 123-144. http://dx.doi.org/10.3354/cr017123

Parkinson, C. L., \& Greenstone, R. (2000). editors. EOS Data Products Handbook Volume 2. NASA Goddard Space Flight Center Greenbelt, Maryland. pp161-162.

Thenkabail, P. S. (1999). Characterization of the alternative to slash-and-burn benchmark research area representing the Congolese rainforests of Africa using near-real-time SPOT HRV data. International Journal of Remote Sensing, 20, 839-877. http://dx.doi.org/10.1080/014311699212966

UNEP. (2004). Fortnam, M. P. \& Oguntola, J. A. (eds), Lake Chad Basin, GIWA Regional assessment 43, University of Kalmar, Kalmar, Sweden. pp 42-74.

Table 1. Household source of income in the Lake Chad basin region (Nami, 2002)

\begin{tabular}{|c|c|}
\hline Activity & Million USD \\
\hline Fishing & 45.10 \\
\hline Rainfed and flood recessional cropping & 26.60 \\
\hline Animal Husbandry & 14.70 \\
\hline Small Irrigated Areas & 10.80 \\
\hline Large Irrigated Areas & 9.40 \\
\hline
\end{tabular}

Table 2. Matrix of correlation coefficent between Year, Projected Population and Fire Count

\begin{tabular}{|c|c|c|c|}
\hline & Year & Population & Fire count \\
\hline Year & 1.0000 & 0.9996 & -0.5273 \\
\hline Population & 0.9996 & 1.0000 & -0.5119 \\
\hline Fire count & -0.5273 & -0.5119 & 1.0000 \\
\hline
\end{tabular}


Table 3. Matrix of probability of significant correlation at $95 \%$ confidence interval

\begin{tabular}{|c|c|c|c|}
\hline & Year & Population & Fire count \\
\hline Year & 1.0000 & 0.0000 & 0.1446 \\
\hline Population & 0.0000 & 1.0000 & 0.1589 \\
\hline Fire count & 0.1446 & 0.1589 & 1.0000 \\
\hline
\end{tabular}

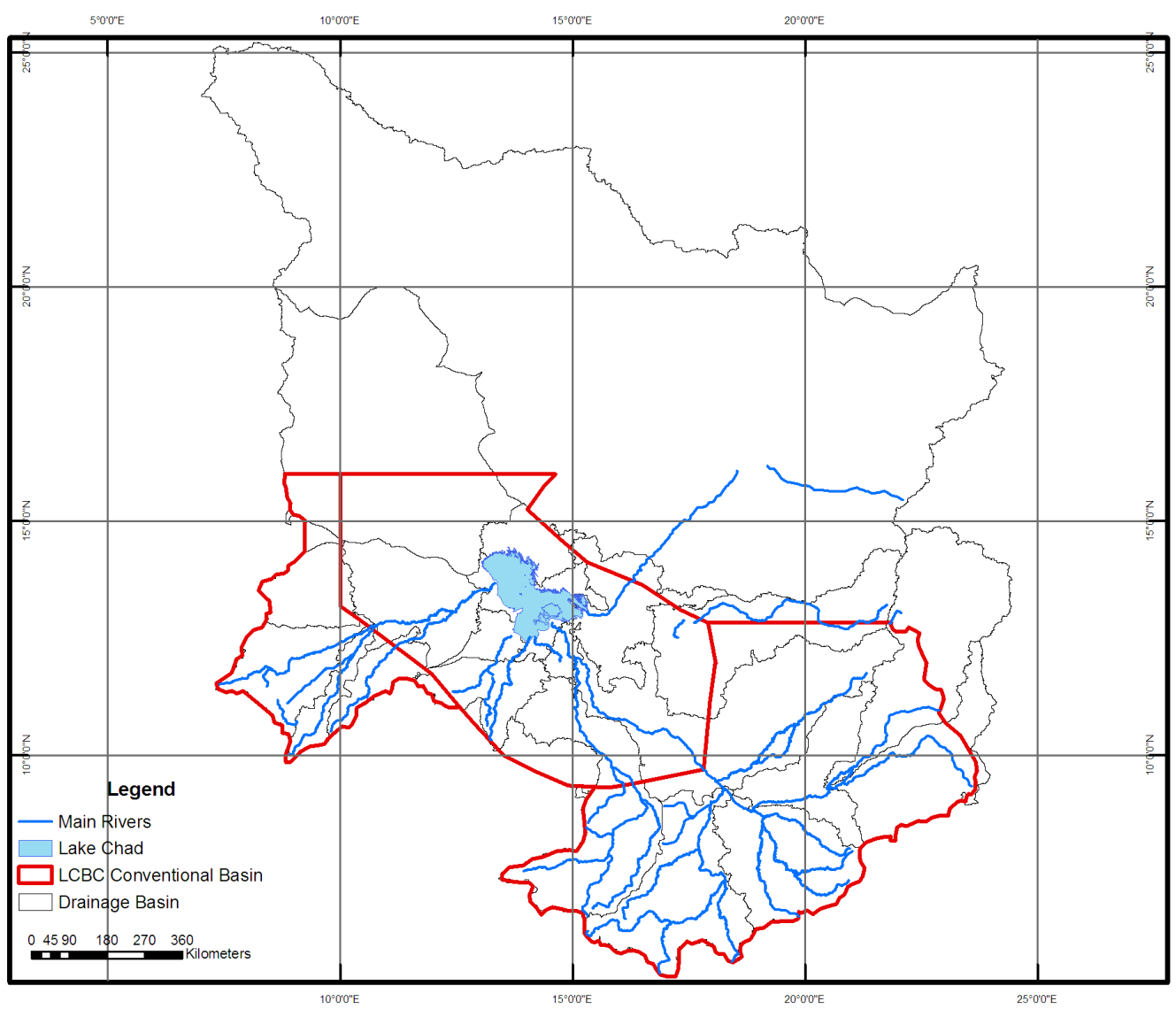

Figure 1. Lake Chad hydrographic watershed showing the LCBC Conventional Basin in red 


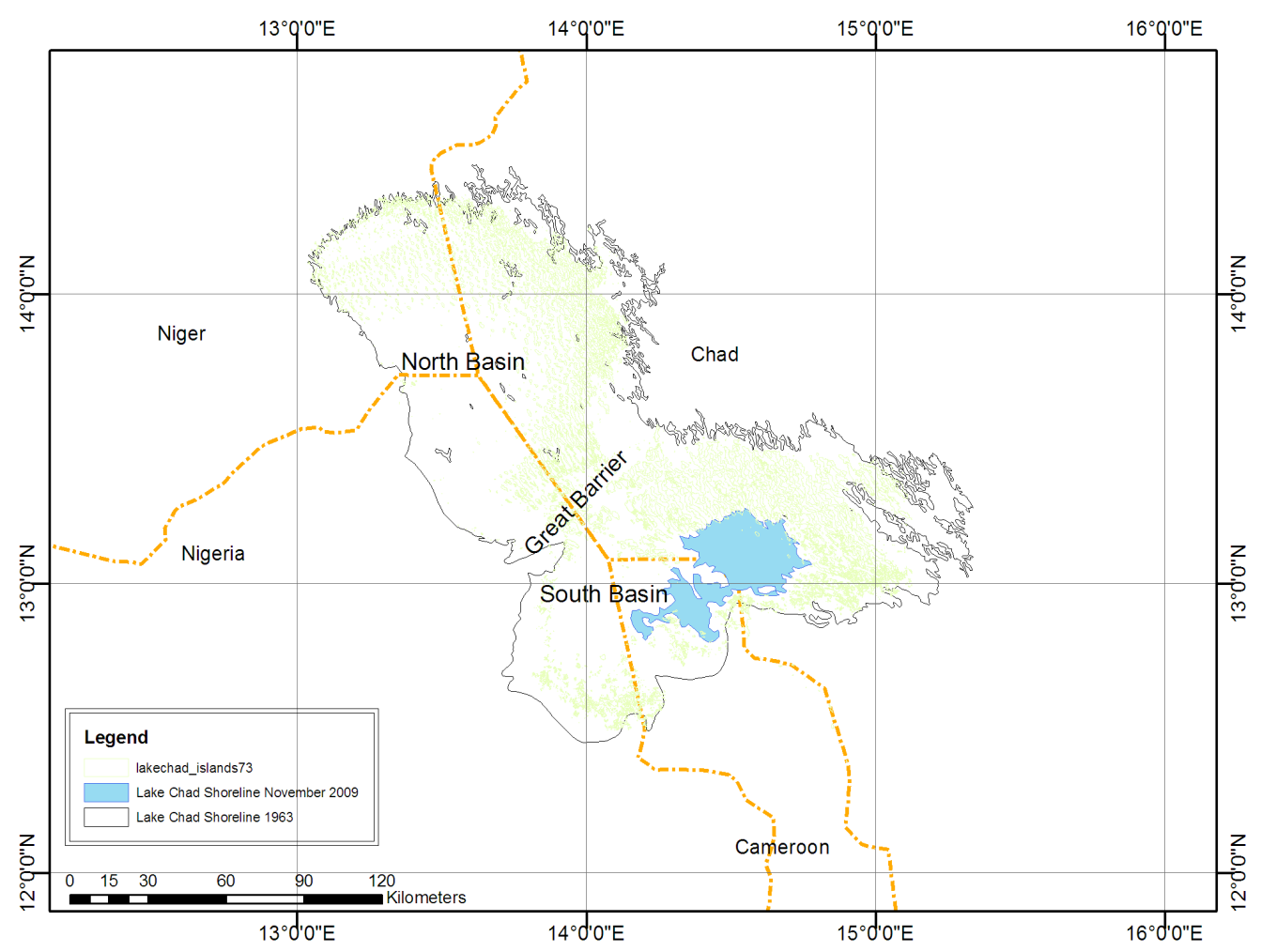

Figure 2. The Lake Chad showing the north and south basins and the study area between the 1963 shoreline and the open water surface as at November 2009

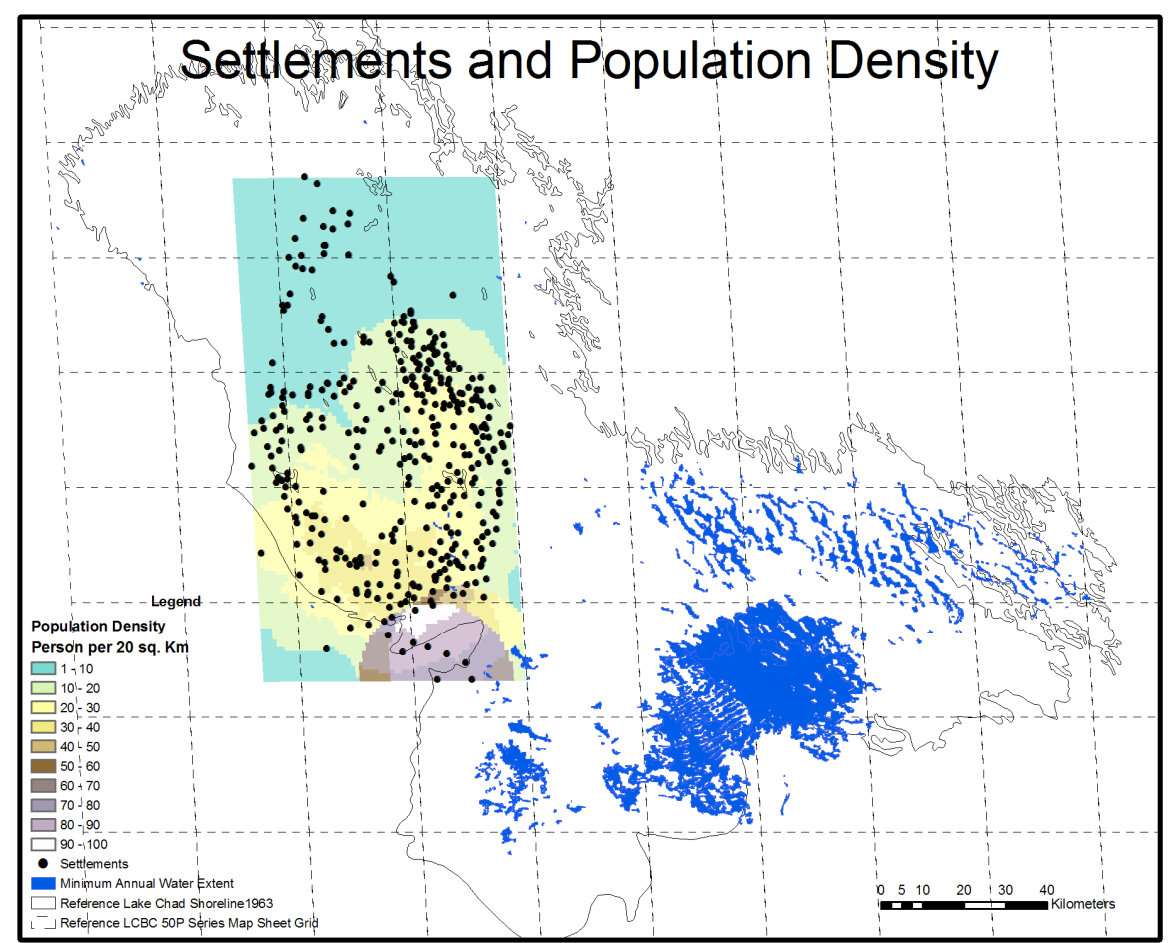

Figure 3. Population density and settlements in the portion of the Lake Chad exhibiting the highest number of fires 